\title{
Clinical Significance of Intravesical Prostatic Protrusion Index in Patients with Clinical Diagnosis of Benign Prostatic Hyperplasia.
}

Seyed Reza Yahyazadeh ( $\nabla$ r.yahyazadeh@gmail.com )

Tehran University of Medical Sciences

Seyed Shahaboddin Izadi

Tehran University of Medical Sciences

\section{Research Article}

Keywords: Intravesical, prostate, protrusion, benign prostatic hyperplasia

Posted Date: March 19th, 2021

DOl: https://doi.org/10.21203/rs.3.rs-329645/v1

License: (c) (1) This work is licensed under a Creative Commons Attribution 4.0 International License.

Read Full License 
Title page:

"Clinical Significance of Intravesical Prostatic Protrusion Index in Patients with Clinical Diagnosis of Benign Prostatic Hyperplasia."

\section{Authors:}

Seyed Reza Yahyazadeh*

Seyed Shahaboddin Izadi

Department of Urology, Shariati Hospital, Faculty of Medicine, Tehran

University of Medical Sciences

* Corresponding autor: Seyed Reza Yahyazadeh

Address: Shariati hospital, North Karegar Ave., Tehran, Iran.

E-mail: r.yahyazadeh@gmail.com, yahyazadeh@sina.tums.ac.ir

15 Keywords: Intravesical, prostate, protrusion, benign prostatic hyperplasia.

Running title: "Clinical Significance of IPP index in BPH". 


\section{Abstract:}

Purpose: To investigate the clinical significance of the intravesical prostatic protrusion (IPP) index in benign prostatic hyperplasia (BPH) patients to clarify its diagnostic value in predicting the clinical and

5 structural abnormalities of the prostate.

\section{Materials and Methods:}

Materials and Methods: In this descriptive and analytical cross-sectional study, we include every man older than 50 years old with lower urinary

10 tract symptoms (LUTS), predominantly voiding or obstructive, suggestive of $\mathrm{BPH}$. The patients were evaluated to determine the following indices: IPSS (International Prostate Symptom Score) Index, QoL (quality of life), prostate volume (PV) and postvoid residual urine (PVR), serum PSA level, and the maximum urinary flow rate (Qmax) obtained by

15 uroflowmetry. Subsequently, the assessment of the IPP index was undertaken by transabdominal ultrasonography. The categorization of the IPP index was done into 3 grades: grade one (below $5 \mathrm{~mm}$ ), grade two (between 5 and $10 \mathrm{~mm}$ ), and grade three (greater than $10 \mathrm{~mm}$ ).

\section{Results:}

The significant direct correlation between the intravesical prostatic protrusion and international prostate symptom score, quality of life, 
prostate volume, postvoid residual urine, and serum PSA as well as inversely with the maximum urinary flow rate was confirmed both before and after the medical treatment. Also, the need for surgical intervention increased significantly with increasing IPP levels.

\section{Conclusion:}

The intravesical prostatic protrusion can be used to evaluate and predict the severity of symptoms and outcomes in patients with clinical BPH. Keywords: Intravesical, prostate, protrusion, benign prostatic hyperplasia.

\section{Introduction:}

Benign prostatic hyperplasia, or $\mathrm{BPH}$, is the most common cause of bladder outflow obstruction in adult men, especially those older than 50 years. Choosing the right patients for the treatment, especially the surgical approaches, is an important issue. Many existing tests and indicators are used to evaluate the patients, including ultrasonographic evaluation, urodynamic tests, and serum biomarkers, which are most valuable in planning the treatment strategy. However, some of these tests have some limitations in clinical practice, especially they are

20 invasive relatively and have potentially significant side effects. Thus, among all diagnostic methods, the non-invasive and readily available 
ultrasound evaluation has been suggested as an effective method. Since the introduction of the intravesical prostatic protrusion index (IPP) evaluated by ultrasonography, the relation between this index and the severity of bladder outflow obstruction has been shown. In the 19th

5 century, the first observations on the characteristics of IPP and its association with prostate and urinary tract diseases were reported. [1] However, until the early 21 st century, the issue of the close relationship between the IPP and BPH had not yet been raised. It was hypothesized then that the IPP index, along with other objective and measurable indicators, may be useful for the evaluation and management of $\mathrm{BPH}$. Besides, there was a close similarity between the results of the IPP measurement by the two means of transrectal and transabdominal ultrasonography and therefore, abdominal ultrasonography was suggested as a suitable tool for the determination of IPP. Overall, based 15 on the available data, bladder outflow obstruction cannot be accurately assessed or confirmed only by clinical symptoms, post voiding residual urine volume, or Qmax index. In this regard, ultrasonography will be able to accurately evaluate the structural abnormalities of the prostate, especially the bladder outflow obstruction, as a widely used and reliable non-invasive method. It seems that the measurement of the IPP index will not only have a high predictive ability to confirm the bladder outflow obstruction but also be able to predict the other clinical and structural 
abnormalities of the prostate. It seems that the use of IPP indices has high sensitivity and diagnostic accuracy in the clinical evaluation of the prostate even in comparison to the urodynamic indices.

The present study aimed to investigate the clinical significance of the

5 IPP index in $\mathrm{BPH}$ patients to clarify its diagnostic value in predicting the clinical and structural abnormalities of the prostate.

\section{Materials and Methods:}

In this descriptive and analytical cross-sectional study, we include every man older than 50 years old with lower urinary tract symptoms (LUTS), predominantly voiding or obstructive, suggestive of BPH. Patients with a history of neurogenic bladder, diabetes mellitus, lumbar disc herniation, spinal trauma/surgery, urethral stricture/injury, or prostate cancer, and those with the absolute indications for surgery were excluded from the

15 study. Informed written consent was taken before the study, based on IR.TUMS.MEDICINE.REC.1396.4107 ethical code of Tehran University of Medical Sciences ethics committee.

After standard clinical approach and making the diagnosis of $\mathrm{BPH}$, the patients were evaluated to determine the following indices: IPSS (International Prostate Symptom Score) Index, QoL (quality of life) index obtained by a single question used to determine the "bother score" which provides a widely used and statistically valid measure [27], 
prostate volume (PV) and postvoid residual urine (PVR) assessed by transabdominal ultrasonography, serum PSA level, and the maximum urinary flow rate (Qmax) obtained by uroflowmetry.

Subsequently, the assessment of the IPP index was undertaken by

5 transabdominal ultrasonography. It should be noted that all the ultrasounds were performed by the same physician and the IPP was defined by the distance between the tip of the prostate's protrusion into the bladder and the bladder neck in sagittal view. (Fig-1)

Figure-1) IPP (white arrow): the distance between the tip of the prostate's protrusion into the bladder and the bladder neck (dashed line) in the sagittal view.

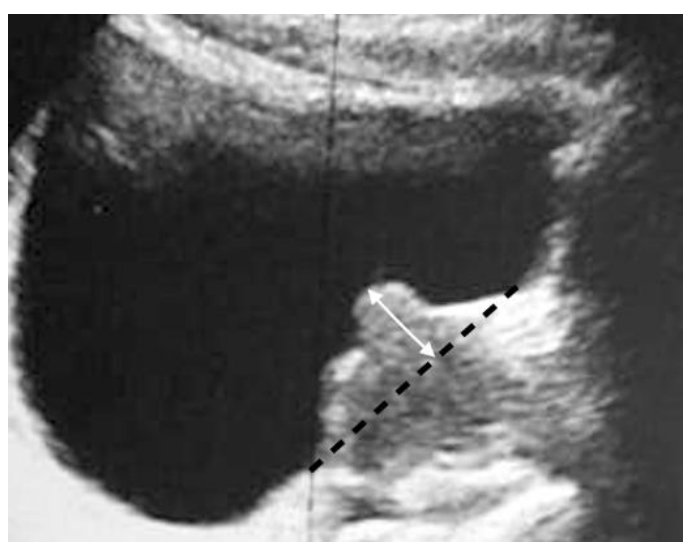

The categorization of the IPP index was done into 3 grades: grade one

15 (below $5 \mathrm{~mm}$ ), grade two (between 5 and $10 \mathrm{~mm}$ ), and grade three (greater than $10 \mathrm{~mm}$ ). 
The results were expressed as mean and standard deviation (mean \pm SD) for the quantitative variables and as percentages for the qualitative ones. SPSS software version 23 was used for statistical analysis and the quantitative variables were analyzed using a t-test or ANOVA test, while

5 the chi-square test was used to compare the qualitative variables.

\section{Results:}

60 patients with the clinical diagnosis of BPH were enrolled in this study and were treated with tamsulosin $0.4 \mathrm{mg}$ daily. The mean follow-up time was $3.97 \pm 1.48$ months (range 1.5 to 7 months). Of the 60 patients evaluated, 23 patients (38.3\%) received finasteride $5 \mathrm{mg}$ daily, concurrently. During the follow-up period, 10 patients (16.7\%) underwent open prostatectomy or transurethral resection of the prostate (TURP). The mean QoL (bother) scores before the treatment were $1.88 \pm 0.88$,

$152.23 \pm 1.09$, and $2.95 \pm 0.89$ for the IPP grades 1,2 , and 3 , respectively, indicating a statistically significant difference between the three groups $(P=0.001)$. Meanwhile, the mean $Q o L$ scores after the medical intervention, were $1.76 \pm 1.01,2.08 \pm 1.04$, and $2.73 \pm 1.35$, respectively, for grades 1,2 , and 3 which again showed a significant difference $(P=0.020)$. (Table-1) 
Table 1: Mean of different study indices in IPP subgroups

\begin{tabular}{|c|c|c|c|c|c|}
\hline & & Grade 1 & Grade 2 & Grade 3 & $\begin{array}{c}\mathrm{p}- \\
\text { value }\end{array}$ \\
\hline \multirow{2}{*}{ Qol } & $\begin{array}{l}\text { Pre- } \\
\text { treatment }\end{array}$ & $\begin{array}{c}1.88 \pm \\
0.88\end{array}$ & $\begin{array}{c}2.23 \\
\pm 1.09\end{array}$ & $\begin{array}{r}2.95 \\
\pm 0.89\end{array}$ & 0.001 \\
\hline & $\begin{array}{l}\text { Post- } \\
\text { treatment }\end{array}$ & $\begin{array}{c}1.76 \\
\pm 1.01\end{array}$ & $\begin{array}{c}2.08 \\
+1.04\end{array}$ & $\begin{array}{c}2.73 \\
\pm 1.35\end{array}$ & 0.020 \\
\hline \multirow{2}{*}{ IPSS } & $\begin{array}{c}\text { Pre- } \\
\text { treatment }\end{array}$ & $\begin{array}{r}10.88 \\
\pm 5.83\end{array}$ & $\begin{array}{c}12.62 \\
\pm 5.04\end{array}$ & $\begin{array}{r}16.36 \\
\pm 5.91\end{array}$ & 0.006 \\
\hline & $\begin{array}{l}\text { Post- } \\
\text { treatment }\end{array}$ & $\begin{array}{r}11.08 \\
\pm 4.98\end{array}$ & $\begin{array}{c}11.54 \\
\pm 4.14\end{array}$ & $\begin{array}{c}17.27 \\
\pm 8.21\end{array}$ & 0.003 \\
\hline PV & $\begin{array}{l}\text { Pre- } \\
\text { treatment }\end{array}$ & $\begin{array}{c}36.68 \\
\pm 16.31\end{array}$ & $\begin{array}{c}34.54 \\
\pm 8.64\end{array}$ & $\begin{array}{r}68.18 \\
\pm 32.99\end{array}$ & $<0.001$ \\
\hline \multirow{2}{*}{ PVR } & $\begin{array}{c}\text { Pre- } \\
\text { treatment }\end{array}$ & $\begin{array}{r}31.20 \\
\pm 36.78 \\
\end{array}$ & $\begin{array}{r}39.31 \\
\pm 40.38 \\
\end{array}$ & $\begin{array}{r}69.14 \\
\pm 81.05 \\
\end{array}$ & 0.038 \\
\hline & $\begin{array}{l}\text { Post- } \\
\text { treatment }\end{array}$ & $\begin{array}{c}21.68 \\
\pm 21.71\end{array}$ & $\begin{array}{c}27.00 \\
\pm 26.70\end{array}$ & $\begin{array}{c}61.77 \\
\pm 59.89\end{array}$ & 0.004 \\
\hline PSA & $\begin{array}{c}\text { Pre- } \\
\text { treatment }\end{array}$ & $\begin{array}{c}1.43 \\
\pm 0.80\end{array}$ & $\begin{array}{c}1.32 \\
\pm 0.68\end{array}$ & $\begin{array}{c}2.79 \\
\pm 0.89\end{array}$ & $<0.001$ \\
\hline \multirow{2}{*}{ Qmax } & $\begin{array}{l}\text { Pre- } \\
\text { treatment }\end{array}$ & $\begin{array}{c}16.21 \\
\pm 4.59\end{array}$ & $\begin{array}{r}12.25 \\
\pm 1.50\end{array}$ & $\begin{array}{c}11.17 \\
\pm 3.09\end{array}$ & 0.002 \\
\hline & $\begin{array}{l}\text { Post- } \\
\text { treatment }\end{array}$ & $\begin{array}{c}18.07 \\
\pm 5.17\end{array}$ & $\begin{array}{r}13.75 \\
\pm 2.99\end{array}$ & $\begin{array}{c}9.83 \\
\pm 3.42\end{array}$ & 0.001 \\
\hline
\end{tabular}

According to Pearson correlation coefficient, there was a significant direct correlation between IPP and Qol (bother) scores either before 5 (correlation coefficient $=0.459, \mathrm{P}<0.001)$ or after the intervention $(\mathrm{cc}=$ $0.353, P=0.006)$. In general, with increasing the IPP score, the quality of life of the patients decreased significantly. (Table-2) 
Table 2: Correlation between different indices and IPP index

\begin{tabular}{|c|c|c|c|}
\hline \multicolumn{2}{|c|}{ Index } & $\begin{array}{c}\text { Correlation } \\
\text { coefficient }\end{array}$ & p-value \\
\hline \multirow{2}{*}{ Qol } & Pre-treatment & 0.459 & $<0.001$ \\
\cline { 2 - 4 } & Post-treatment & 0.353 & 0.006 \\
\hline \multirow{2}{*}{ IPSS } & Pre-treatment & 0.397 & 0.002 \\
\cline { 2 - 4 } & Post-treatment & 0.401 & 0.001 \\
\hline \multirow{2}{*}{ PV } & Pre-treatment & 0.504 & 0.001 \\
\hline \multirow{2}{*}{ PVR } & Pre-treatment & 0.293 & 0.029 \\
\cline { 2 - 4 } & Post-treatment & 0.399 & 0.002 \\
\hline \multirow{2}{*}{ PSA } & Pre-treatment & 0.566 & $<0.001$ \\
\hline \multirow{2}{*}{ Qmax } & Pre-treatment & -0.552 & $<0.001$ \\
\cline { 2 - 5 } & Post-treatment & -0.695 & $<0.001$ \\
\hline
\end{tabular}

The mean IPSS scores of patients, before the treatment, for grade 1, 2, and 3 subgroups were $10.88 \pm 5.83,12.62 \pm 5.04 \%$, and $16.36 \pm 5.91$,

5 respectively. In other words, as the IPP increased, the patients' IPSS score also increased $(P=0.006)$.

After the medical intervention, the mean IPSS scores were $11.08 \pm 4.98$, $11.54 \pm 4.14$, and $17.27 \pm 8.21$, respectively. $(P=0.003)$. According to Pearson correlation coefficient, there was a significant direct correlation 
between the IPP and IPSS scores either before $(\mathrm{cc}=0.397, \mathrm{P}=0.002)$ or after the treatment $(\mathrm{cc}=0.40, \mathrm{P}=0.001)$.

Regarding the relationship between the IPP and PV indices (before treatment), mean PV for IPP subgroup grades 1, 2, and 3 were $36.68 \pm$

$516.31,34.54 \pm 8.64$, and $68.18 \pm 32.99$, respectively. In this regard, the grade 3 patients with IPP $>10 \mathrm{~mm}$ had significantly higher PV than the other two subgroups $(P<0.001)$. There was a significant direct correlation between IPP and PV indices $(c c=0.504, P=0.001)$. In evaluating the correlation between the IPP and PVR indices, the mean PVR of patients before treatment for IPP subgroups 1, 2, and 3 was $31.20 \pm 36.78,39.31 \pm 40.38$, and $69.14 \pm 81.05$, respectively. In other words, as the IPP increased, the patients' PVR also increased ( $P=$ 0.038). After the medical intervention, the mean PVR for the IPP subgroups was $21.68 \pm 21.71,27.00 \pm 26.70$, and $61.77 \pm 59.89$, respectively. It was again indicating a significant difference between the three groups $(P=0.004)$. According to the Pearson correlation coefficient, there was a significant direct correlation between the IPP and PVR indices before $(\mathrm{cc}=0.293, \mathrm{P}=0.029)$ and after the medical intervention $(c c=0.399, P=0.002)$.

20 The mean PSA level for the IPP grade 1, 2, and 3 subgroups were 1.43 $\pm 0.80,1.32 \pm 0.68$, and $2.79 \pm 0.89$ respectively. The patients with IPP greater than $10 \mathrm{~mm}$ had a significantly higher PSA level than the other 
two subgroups $(P<0.001)$. In this regard, there was a significant direct correlation between the IPP score and the PSA level $(\mathrm{cc}=0.556, \mathrm{P}<$ $0.001)$.

In evaluating the correlation between IPP value and Qmax index, the

5 mean Qmax of patients before treatment for IPP grade 1, 2, and 3 subgroups were $16.21 \pm 4.59,12.25 \pm 1.50$, and $11.17 \pm 3.09$ respectively; which showed that with increasing IPP index, the Qmax of the patients decreased significantly $(P=0.002)$. Meanwhile, after the medical intervention, the mean Qmax of patients became 18.07 \pm 5.17 ,

$10 \quad 13.75 \pm 2.99$, and $9.83 \pm 3.42$, respectively; which was again indicating a significant difference between the three groups $(P=0.001)$. According to the Pearson correlation coefficient, there was a significant inverse correlation between the IPP score and the Qmax both before $(\mathrm{cc}=-$ $0.555, \mathrm{P}<0.001)$ and after the medical intervention $(\mathrm{cc}=-0.695, \mathrm{P}<$ $150.001)$.

Finally, the prevalence of the need for the surgical intervention in the IPP grade 1,2 , and 3 subgroups were $4 \%, 7.7 \%$, and $36.4 \%$, respectively, which showed a significant difference between the subgroups so that the need for surgery increased with the IPP score increase $(P<0.007)$. (Fig2)

Figure-2) Frequency of the surgical intervention need in IPP grade groups. $(P<0.007)$ 


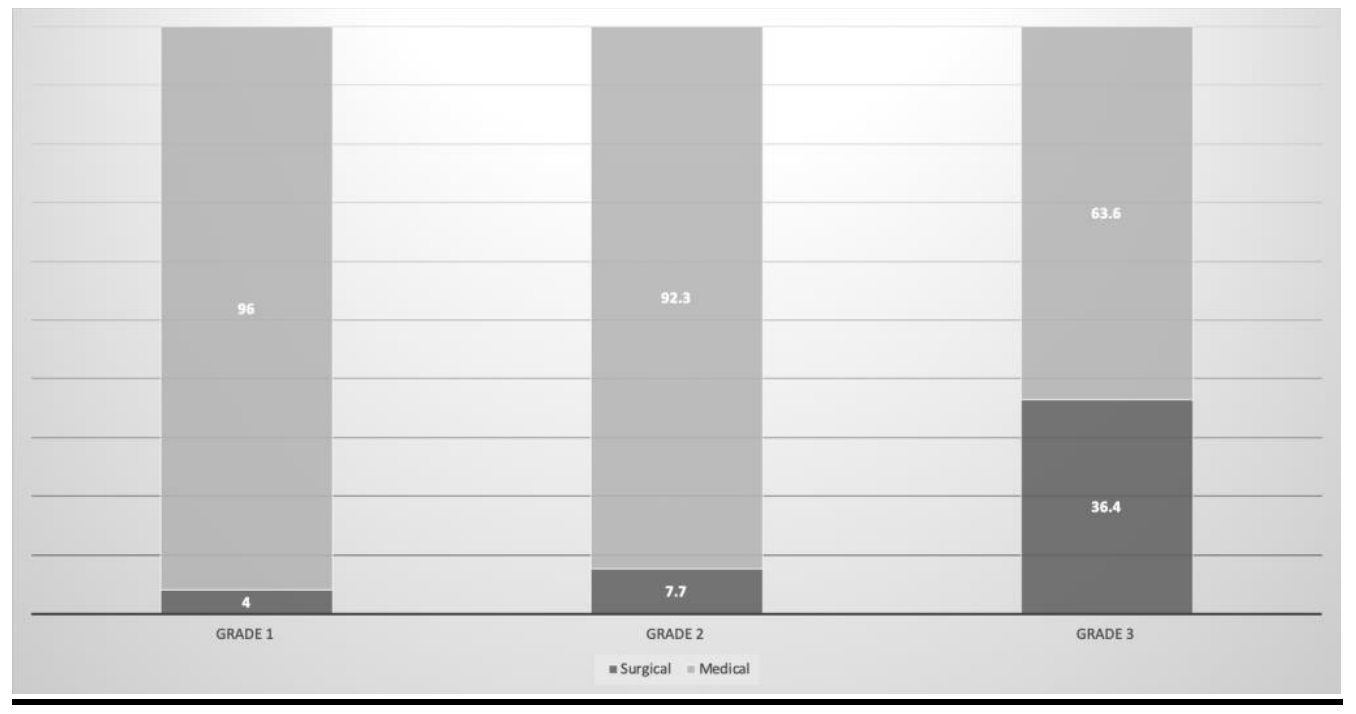

\section{Discussion:}

Our results show a direct correlation between the IPP index and the QoL, IPSS, PV, PVR, and PSA indices as well as inversely with the Qmax index before and after BPH medical therapy. It was also found

10 that the need for surgical intervention increased significantly with increasing IPP levels.

As mentioned before, there are various invasive and non-invasive indices for evaluating, diagnosing, and predicting the severity of $\mathrm{BPH}$. In this regard, PSA, PVR, PV, and Qmax are mentioned. The main reason

15 for the researchers' interest in finding other markers or indicators for $\mathrm{BPH}$, is the low sensitivity and specificity of these methods in predicting 
$\mathrm{BPH}$ outcomes, as well as evaluating the severity of $\mathrm{BPH}$-induced bladder outflow obstruction, and in particular the distinction between $\mathrm{BPH}$ and prostate cancer.

In this regard, special attention has recently been paid to the index of

5 prostate protrusion into the bladder or IPP, and various studies have been conducted on the diagnostic value of IPP in the diagnosis and prediction of $\mathrm{BPH}$ and its severity. What emphasized in the studies, and in particular in the present study, was the correlation between IPP and other indicators used in the BPH assessment mentioned above.

What we did in the present study was to evaluate the correlation between IPP and the classification provided for it with other indices used to assess $\mathrm{BPH}$ and predict the need for surgical intervention in these patients. There was no similar study on the need for surgical intervention during the follow-up period. However, the small sample size and the 15 relative shortness of the follow-up period are shortcomings of our study. As mentioned, similar studies have yielded similar results to our findings. In the study of Liu et al, and contrary to our study, although there were significant changes in total prostate volume and volume of the transitional zone following drug treatment, no significant change was

20 observed in the degree of IPP. [28] In the study of Suzuki et al, and quite similar to our study, the bladder output obstruction index was positively correlated with the IPP index. 
Among all the indices mentioned above, the highest ability to predict $\mathrm{BPH}$ was related to IPP. [29]

Wang et al showed a strong and significant relationship between the prostate volume and the degree of IPP. There was also an inverse

5 relationship between IPP and Qmax, which was consistent with our results. [30]

And in the study of Lee et al, the two indices of total prostate and transitional zone volume were different between the two groups of IPP, which was similar to our study, but the change in other indices such as Qmax and PVR was not correlated with IPP, which was not consistent with our study. [12]

What seems to be responsible for different findings of various studies is the factors related to the experience of the operator evaluating the ultrasonographic or urodynamic indices as well as the different sample 15 sizes and power of the mentioned studies.

In this study and line with previous studies, a direct correlation between IPP and QoL, IPSS, PV, PVR, and PSA indices was confirmed, both before and after treatment for $\mathrm{BPH}$. Also, the inverse correlation between IPP and Qmax before and after the medical intervention was confirmed. In other words, it can be concluded that the amount of prostate gland protrusion into the bladder is physically correlated with the severity of the $\mathrm{BPH}$, increasing the size of the prostate, decreasing 
the quality of life of the patients, and also decreasing the flow of the bladder outflow and as a representative of each of the above indicators can be used to evaluate BPH and its consequences.

\section{Conclusion:}

As a general conclusion, there was a direct correlation between the IPP index and QoL, IPSS, PV, PVR, and PSA indices as well as inversely with the Qmax index before and after medical treatment. Also, the need for surgical intervention increases significantly with increasing IPP levels. Therefore, the IPP index can be used to evaluate and predict the severity of symptoms and outcomes in patients with clinical BPH.

\section{Declarations:}

- Ethics approval and consent to participate: The study was approved by the ethics committee of the school of medicine - Tehran University of Medical Sciences (IR.TUMS.MEDICINE.REC.1396.4107). After written informed consent forms completion by patients then the local human subjects' review board approval, all methods were carried out in accordance with relevant professional guidelines and regulations.

- Consent for publication: All patients and volunteers were provided with written informed consent. 
- Availability of data and materials: The data that support the findings of this study are available from the corresponding author, SRY, upon reasonable request.

- Competing interests: All authors claim that there is not any conflict

5 of interest for this publication.

- Funding: This research was not supported by any grant or funding.

- Authors' contributions: Both of the authors contributed to the study conception, design, and the writing and review of the manuscript.

- Acknowledgements: The authors would like to express their gratitude to the Tehran University of Medical Sciences (TUMS).

\section{References:}

1. Mehraban D, Naderi GH, Yahyazadeh SR, Amirchaghmaghi M. Sexual dysfunction in aging men with lower urinary tract symptoms. Urology Journal. $2008 ; 5(4): 260-264$.

2. Mehraban D. Clinical value of intravesical prostatic protrusion in the evaluation and management of prostatic and other lower urinary tract diseases. Asian J Urol. 2017 Jul; 4(3):174-180. doi: 10.1016/ j. ajur. 2016.10.001. Epub 2017 Jan 20.

3. Ohnishi K, Watanabe H, Ohe H, Saitoh M. Development and clinical significance of protrusion of hypertrophic prostate into the 
bladder observed by transrectal ultrasonotomography. Nihon Hinyokika Gakkai Zasshi 1985; 76: 1194e200.

4. Watanabe H. New concept of BPH: PCAR theory. Prostate 1998; $37: 116 \mathrm{e} 25$.

5. Yuen JSP, Ngiap JTK, Cheng CWS, Foo KT. Effects of bladder volume on transabdominal ultrasound measurements of intravesical prostatic protrusion and volume. Int J Urol 2002; 9:225e9.

6. Chia SJ, Heng CT, Chan SP, Foo KT. Correlation of intravesical prostatic protrusion with bladder outlet obstruction. BJU Int 2003; 91:371e4.

7. Kuo TL, Teo JS, Foo KT. The role of intravesical prostatic protrusion (IPP) in the evaluation and treatment of bladder outlet obstruction (BOO). Neurourol Urodyn 2016; 35:535e7.

8. Nose H, Foo KT, Lim KB, Yokoyama T, Ozawa H, Kumon H. Accuracy of two noninvasive methods of diagnosing bladder outlet obstruction using ultrasonography: intravesical prostatic protrusion and velocity-flow video urodynamics. Urology 2005; 65:493e7.

9. Tan $\mathrm{YH}$, Foo KT. Intravesical prostatic protrusion predicts the outcome of a trial without catheter following acute urine retention. $\mathrm{J}$ Urol 2003; 170(6 Pt 1):2339e41. 
10. Syazarina Sharis O, Zulkifli MZ, Hamzaini AH. Predicting the outcome of trial of voiding without catheter in acute urinary retention with intravesical prostatic protrusion. Malays J Med Sci 2013; 20:56e9.

11. Kalkanli A, Tandogdu Z, Aydin M, Karaca AS, Hazar AI, Balci MB, et al. Intravesical prostatic protrusion: a potential marker of alphablocker treatment success in patients with benign prostatic enlargement. Urology 2016; 88:161e5.

12. Lee JW, Ryu JH, Yoo TK, Byun SS, Jeong YJ, Jung TY. Relationship between Intravesical Prostatic Protrusion and Postoperative Outcomes in Patients with Benign Prostatic Hyperplasia. Korean J Urol. 2012 Jul;53(7):478-82. doi: 10.4111/kju.2012.53.7.478. Epub 2012 Jul 19.

13. Kim MS, Park KK, Chung BH, Lee SH. Effect of photoselective vaporisation prostatectomy on lower urinary tract symptoms in benign prostatic hyperplasia with or without intravesical prostatic protrusion. Korean J Urol 2013;54: S36e41.

14. Gandhi J, Weissbart SJ, Kim AN, Joshi G, Kaplan SA, Khan SA. Clinical Considerations for Intravesical Prostatic Protrusion in the Evaluation and Management of Bladder Outlet Obstruction Secondary to Benign Prostatic Hyperplasia. Curr Urol 2018;12:612. 
15. Hirayama K, Masui K, Hamada A, Shichiri Y, Masuzawa N, Hamada S. Evaluation of intravesical prostatic protrusion as a predictor of dutasteride-resistant lower urinary tract symptoms/benign prostatic enlargement with a high likelihood of surgical intervention. Urology 2015; 86:565e9.

16. Lee LS, Sim HG, Lim KB, Wang D, Foo KT. Intravesical prostatic protrusion predicts clinical progression of benign prostatic enlargement in patients receiving medical treatment. Int J Urol $2010 ; 17: 69 \mathrm{e} 74$.

17. Kim JW, Oh MM, Park HS, Cheon J, Lee JG, Kim JJ, et al. Intravesical prostatic protrusion is a risk factor for bladder stone in patients with benign prostatic hyperplasia. Urology 2014; 84:1026e9.

18. Tong YC, Lin YM, Yang WH, Tzai TS, Lin JS. Correlation of transrectal ultrasonographic findings of the prostate with the occurrence of detrusor instability in patients with benign prostatic hyperplasia. Urol Int 1995; 55:154e7.

19. Lee JM, Chung H, Kim TW, Kim HS, Wang JH, Yang SK. The correlation of intravesical prostatic protrusion with storage symptoms, as measured by transrectal ultrasound. Korean J Urol 2008; 49:145e9. 
20. Kim KH, Kim YS. Correlation of male overactive bladder with intravesical prostatic protrusion. Korean J Urol 2010;51: 843e6.

21. Xu D, Yu Y, Zhu Y, Huang T, Chen Y, Qi J. A new model consists of intravesical prostatic protrusion, prostate polume, and serum prostatic-specific antigen in the evaluation of prostate cancer. Pathol Oncol Res 2014; 20:439e43.

22. Lee $\mathrm{CH}, \mathrm{Ha} \mathrm{HK}$. Intravesical prostatic protrusion as a predictor of early urinary continence recovery after laparoscopic radical prostatectomy. Int J Urol 2014; 21:653e6.

23. Doo CK, Uh HS. Anatomic configuration of prostate obtained by noninvasive ultrasonography can predict clinical voiding parameters for determining BOO in men with LUTS. Urology. 2009; 73:232-236.

24. Mariappan P, Brown DJ, McNeill AS. Intravesical prostatic protrusion is better than prostate volume in predicting the outcome of trial without catheter in white men presenting with acute urinary retention: a prospective clinical study. J Urol. 2007; 178:573-577.

25. Rosier PF, de Wildt MJ, Wijkstra H, Debruyne FF, de la Rosette JJ. Clinical diagnosis of bladder outlet obstruction in patients with benign prostatic enlargement and lower urinary tract symptoms: development and urodynamic validation of a clinical prostate score 
for the objective diagnosis of bladder outlet obstruction. $\mathrm{J}$ Urol. 1996; 155:1649-1654.

26. el Din KE, Kiemeney LA, de Wildt MJ, Rosier PF, Debruyne FM, de la Rosette JJ. The correlation between bladder outlet obstruction and lower urinary tract symptoms as measured by the international prostate symptom score. J Urol. 1996; 156:1020-1025.

27. O'leary MP. Validity of the "bother score" in the evaluation and treatment of symptomatic benign prostatic hyperplasia. Rev Urol. 2005;7(1):1-10.

28. Liu Q, Zhu Y, Liu J, Qi J, Kang J. Ultrasound image features of intravesical prostatic protrusion indicated failure of medication therapy of finasteride and doxazosin in patients with benign prostatic hyperplasia (LUTS/BPH). Int Urol Nephrol. 2016 Dec 16.

29. Suzuki T, Otsuka A, Ozono S. Combination of intravesical prostatic protrusion and resistive index is useful to predict bladder outlet obstruction in patients with lower urinary tract symptoms suggestive of benign prostatic hyperplasia. Int J Urol. 2016 Nov;23(11):929933. doi: 10.1111/iju.13188. Epub 2016 Aug 21.

30. Wang D, Huang H, Law YM, Foo KT. Relationships between Prostatic Volume and Intravesical Prostatic Protrusion on Transabdominal Ultrasound and Benign Prostatic Obstruction in 
Patients with Lower Urinary Tract Symptoms. Ann Acad Med Singapore. 2015 Feb;44(2):60-5. 


\section{Figures}

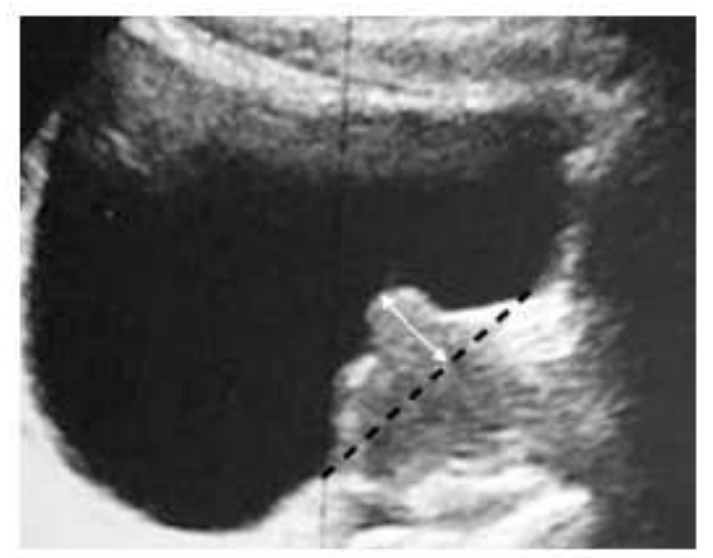

\section{Figure 1}

IPP (white arrow): the distance between the tip of the prostate's protrusion into the bladder and the bladder neck (dashed line) in the sagittal view.

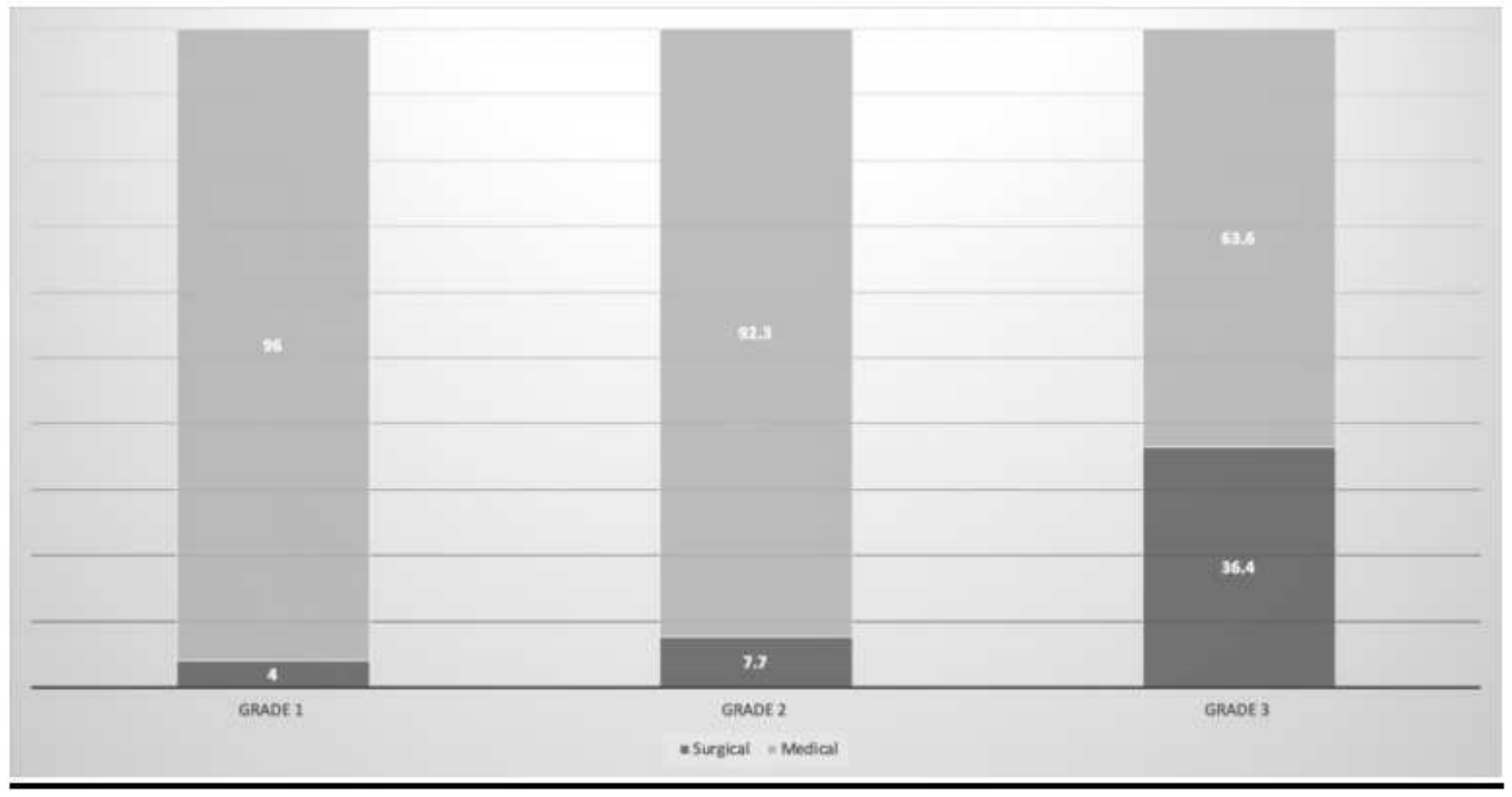

Figure 2

Frequency of the surgical intervention need in IPP grade groups. $(P<0.007)$ 